\title{
RESPONSABILIDADE SOCIAL: IDEOLOGIA, PODER E DISCURSO NA LOGICA EMPRESARIAL
}

\section{RESUMO}

O objetivo do artigo é identificar como uma empresa multinacional de papel e celulose desenvolve programas sociais em uma região compreendida por 47 municípios no estado de Minas Gerais. A escolha da empresa $X$ foi definida pela sua importância na indústria mineira, bem como pelo destaque dado aos programas sociais da empresa no meio empresarial, que vivencia iniciativas centralizadas de incentivo ao voluntariado. Foi realizada uma pesquisa bibliográfica sobre a concepção da responsabilidade social empresarial e uma pesquisa de campo qualitativa com agentes sociais na região de atuação da empresa. A metodologia empregada na pesquisa foi construída por meio de um conjunto de entrevistas semiestruturadas, utilizando a análise do discurso como técnica para pontuação das conclusões do trabalho. O s resultados demonstram que a prática da responsabilidade social se situa num contexto mais significativo que o mero discurso empresarial.

\section{Epaminondas Bittencourt}

UFMG

\section{Alexandre Carrieri}

UFMG

\begin{abstract}
This article show how a multinational company that produces paper and pulp in 47 municipalities in the Brazilian state of Minas Gerais develops social programs. Choice of company X was due to its importance in the industrial web of the state, as well as by the relevance of the company's well regarded social programs, generally centrally managed and emphasizing voluntary work. After a brief survey of the liter ature on corporate social responsibility a field research followed using as subjects social agents in the region covered by company $\mathrm{X}$ programs. M ethodology was based on semi-structured interviews. Content analysis of interviews was punctuated to reach the conclusions. The results demonstrate that the social responsibility practice is situated at a deeper context than allowed by managerial discourse.
\end{abstract}

PALAVRAS-CHAVE Poder, responsabilidade social, cidadania corporativa, responsividade social.

KEYWORDS Power, social responsibility, corporate citizenship, social responsiveness. 


\section{INTRODUÇÃO}

O objetivo do artigo é identificar como uma empresa multinacional do setor econômico de papel e celulose desenvolve programas sociais via ideologia da responsabilidade social, estando envolvidas rel ações com agentes políticos, ambientalistas, microempreendedores e lideranças comunitárias em uma microrregião composta por 47 municípios no estado de Minas Gerais. A empresa possui importante presença regional devida aos tributos pagos e empregos gerados, e também pelos programas sociais por ela implementados. As atividades produtivas da empresa têm sido vistas de maneira discordante, envolvendo diferentes atores sociais, que questionam as políticas desenvolvidas que buscariam construir uma imagem socialmente responsável.

0 artigo apresenta uma perspectiva da cidadania corporativa como uma relação de poder em que cabe aos diferentes agentes (stakehol ders) negociar os interesses próprios com as corporações. 0 referencial teórico está estruturado em pesquisa bibliográfica que abrange diversas concepções sobre a responsabilidade social, culminando numa análise acerca da difusão dos val ores da cidadania corporativa em todo o universo empresarial, o que leva à geração de movimentos diferenciados com o mesmo objetivo: a veiculação de uma imagem social mente responsável. Tais movimentos, que variam de ações centralmente planejadas por associações empresariais, como 0 incentivo ao voluntariado, a programas focalizados de cunho filantrópico, resultam da avaliação de que as organizações operam em um ambiente social que exige mais do que somente as obrigações legais e financeiras (M cintosh, 2001). A metodologia de pesquisa desenvolvida no estudo de caso é qualitativa, baseada em um conjunto de entrevistas semiestruturadas, com a utilização da análise do discurso dos personagens envolvidos, sendo observadas as formações discursivas públicas da organização, expressas por meio do código de ética e pela fala gerencial, bem como as formações discursivas de agentes enunciadores vivenciando relações conflituosas com a organização. A conclusão do trabal ho mostra que a ideologia da responsabilidade social ultrapassa as fronteiras do discurso hegemônico da importância da ética na condução dos negócios, situando-se em um contexto de relações de poder em que ocorrem conflitos envolvendo dominação e subordinação.

\section{REFERENCIAL TEÓRICO}

\section{Corporação e sociedade}

Qual o papel desempenhado pelas corporações na sociedade? Esta pergunta é fonte de um considerável debate no meio acadêmico e no interior das próprias corporações, originando um grande número de trabaIhos baseados em teorias econômicas e organizacionais. Os relacionamentos entre indústrias, mercados e sociedade, no auge da produção industrial, deram origem ao conceito de responsabilidade social das empresas, fruto da crescente importância das atividades industriais no contexto social, envolvendo interferências no meio ambiente, infra-estrutura urbana, relacionamento humano e mudanças de val ores culturais nas comunidades industriais.

A presentando a responsabilidade social como a obrigação das corporações em perseguir políticas, tomar decisões e seguir linhas de ação em consonância com objetivos e valores desejáveis pela sociedade, Howard Bowen, em sua obra Social Responsabilities of the Businessman (1953), estabeleceu a associação entre as operações em Iarga escala das corporações e seus diversos impactos na sociedade como um todo (Preston, 1975). A definição de Bowen de responsabilidade social com ênfase em objetivos e valores sociais expressa duas premissas importantes: a de que as corporações devem a razão de sua existência a um contexto social e que essas corporações são agentes sociais que refletem e reforçam valores (Wartick e Cochran, 1985). Relacionado à primeira premissa, está em vigor um contrato social constituído de direitos e obrigações que fundamentam a legitimidade do negócio, e associada à segunda premissa, a capacidade das corporações de desenvolverem políticas e regras que interferem no ambiente social. Portanto, "uma dimensão ética para 0 comportamento e responsabilidade social do negócio é o resultado lógico" (Wartick e Cochran, 1985, p. 758).

De acordo com Preston (1975), a partir do desenvolvimento do trabal ho de Bowen, surgiram três principais correntes teóricas fundamentando conceitos sobre o papel das corporações na sociedade: a institucionalista, a organizacional e a filosófica. 0 foco dos institucionalistas está na rel ação das corporações com 0 universo social mais amplo. As contribuições teóricas situadas no campo organizacional compreendem a relação corporação-sociedade em um universo localizado no âmbito das organizações, regidas, principalmente, pela el eição da estratégia como instrumento destinado a promover a adaptação das corporações às 
mudanças ambientais. A análise filosófica se baseia, sobretudo, em concepções teóricas prescritivas com relação à responsabilidade social, estando aí situadas posições de cunho neoliberal, filantrópicas e de maior comprometimento com questões sociais por parte das corporações.

Jones (1983) afirma que os estudos sobre a relação corporação-sociedade carecem de um paradigma teórico no estrito sentido definido por Kuhn (1970) devido à ausência de uma estrutura de pesquisa integrada, ou seja, teorias, métodos e valores unificadores. 0 autor propõe uma estrutura integrada para a análise do relacionamento corporação-sociedade, baseada nos trabalhos de Daniel Bell - na obra The Cultural Contradictions of Capitalism (1976) - e Michael N ovak na obra The Spirit of Democratic Capitalism (1982) -, que visualizam a sociedade como o resultado de três subsistemas: econômico, político e cultural. 0 subsistema econômico é composto pelas corporações privadas, públicas, mercados financeiros; o subsistema político deriva do aparel ho regulador governamental; e o subsistema cultural é composto pelas relações familiares, credos e valores socioculturais.

Ainda de acordo com Jones (1983), a compreensão da relação corporação-sociedade é possível por meio do estudo da interação dos três subsistemas, o que resulta na definição de controle social do negócio. 0 controle social do negócio deve ser trabal hado a partir da seguinte questão: qual a compatibilidade entre os processos e produtos do subsistema econômico com os valores dos subsistemas político e cultural? 0 autor propõe uma matriz de controle social do negócio em que se estabelecem variáveis associadas, entre outras, ao controle de mercado, ao comportamento em processos decisórios e à existência de grupos de poder que exercem pressão sobre a corporação.

Em oposição ao conceito de responsabilidade social conduzindo o relacionamento corporação-sociedade, Preston e Post (1981) afirmam que corporação e sociedade são apenas sistemas interligados por intermédio dos mercados e políticas públicas: a contraposição envolvendo responsabilidade social por parte das corporações é aprofundada por Levitt (1958) com relação aos postulados apresentados por Bowen (1953). De acordo com Levitt (1958), as corporações deveriam reconhecer as funções do governo e permitir que este cuidasse do bem-estar social, de forma que elas pudessem cuidar dos aspectos materiais do bem-estar. $\mathrm{Na}$ concepção desse autor, a função do negócio é gerar um alto nível sustentável de lucro:
A essência da empresa livre é se dirigir rumo ao lucro por qualquer caminho que seja consistente com sua própria sobrevivência em um sistema econômico. A queda nos lucros não é a única coisa que pode destruir um negócio. A ossificação burocrática, uma legislação hostil e uma revolução podem fazer isso muito melhor. 0 capitalismo como o conhecemos pode existir somente em um ambiente de democracia política e liberdade pessoal. Isso requer uma sociedade pluralista, onde exista divisão e não centralização de poder. Não queremos um estado de bem-estar no governo, não o queremos nos sindicatos e, pelas mesmas razões, não o desejamos nas corporações (LEVITT, 1958, p. 44).

$\mathrm{Na}$ análise de Levitt, por melhores que sejam as intenções dos gerentes das organizações por meio de ações de desenvolvimento de programas de bem-estar para os empregados, de envolvimento com programas governamentais, comunitários, filantrópicos, educacionais, são todas preocupações periféricas que podem criar, nas corporações, um model o equival ente ao Estado unitário ou à igreja medieval. 0 autor afirma que "se existe al guma coisa errada hoje é que as corporações estão concebendo suas ambições e necessidades muito amplamente. A verdade não é que elas sejam estritamente orientadas para o lucro, mas sim que elas não são estritamente orientadas para 0 lucro" (Levitt, 1958, p. 44). Sob o envolvimento social, o poder que a corporação ganha como "igreja comercial", ela o perderá como um agente capitalista motivado pelo lucro (Levitt, 1958, p. 46). Assim, ainda para o autor, os negócios precisam sobreviver, e precisam de segurança contra ataques e restrições do seu maior inimigo potencial, que é o Estado. 0 bemestar e a sociedade não fazem parte do negócio das corporações. As idéias defendidas por Levitt (1958) acerca do controle social dos negócios são semel hantes, em sua totalidade, às posições teóricas sustentadas por Hayeck em relação à doutrina liberal na sociedade:

A argumentação liberal propugna pelo melhor uso possível das forças de competição como um meio de coordenar os esforços humanos e não pretende que as coisas devam ser deixadas como estão. É baseada na convicção de que onde se puder criar uma efetiva concorrência, aí se terá a melhor maneira, entre todas, de guiar os esforços individuais. Com efeito, um dos principais argumentos 
a favor da concorrência é que ela dispensa a necessidade de um controle social consciente (HAYECK, 1977, p. 35).

Seguindo o mesmo espectro ideológico, Friedman (1988) aborda a responsabilidade econômica das corporações fundamentada na doutrina econômica clássica, em oposição às premissas da responsabilidade social corporativa. De acordo com esse autor, a única responsabilidade social dos negócios é maximizar os lucros nas regras do jogo. Em suas palavras,

Há poucas coisas capazes de minar tão profundamente as bases de nossa sociedade livre como a aceitação por parte dos dirigentes das empresas de uma responsabilidade social que não a de fazer tanto dinheiro quanto possível para seus acionistas. Trata-se de uma doutrina fundamentalmente subversiva. Se os homens de negócios têm outra responsabilidade social que não a de obter o máximo de lucro para seus acionistas, como poderão eles saber qual seria ela? Podem decidir sobre que carga impor a si próprios e a seus acionistas para servir ao interesse social? (FRIEDMAN, 1988, p. 120).

Expressando uma visão sobre a crescente preocupação das corporações em relação à doutrina da responsabilidade social, Frederick (1960) enfatizou que isso se deve ao colapso do laissez-faire como filosofia e ordem econômica. Segundo esse autor, essa revolução é resultado dos desafios estabelecidos pela psicologia ao conceito de um homem econômico racional, pela sociologia ao comportamento individualista e pela antropologia ao questionamento da ordem natural das coisas. A derrocada da filosofia do liberalismo deu origem a um vácuo filosófico após o fim da Segunda Guerra Mundial, o que implicou a ruptura com a teoria social que estabelecia a harmonia entre os interesses privados e os interesses da sociedade como um todo.

Conseqüentemente, a partir da década de 1950 surgiram, na sociedade americana, cinco importantes correntes teóricas sobre a responsabilidade social das corporações. A primeira visão é a de que os gerentes deveriam voluntariamente defender os interesses públicos utilizando o poder de uma maneira responsável. A segunda apela para os princípios da ética cristã, a criação do executivo de negócios cristão, que privilegia ações sociais nobres acima das atividades cotidia- nas das corporações. A terceira está fundamentada na necessidade de construção de um poder na sociedade que se contraponha ao crescente poder das corporações industriais, sendo o bem-estar social dependente da soma de interesses representados na luta pelo poder na sociedade. A quarta, representada por correntes teóricas filosóficas humanistas, associa o poder social das corporações ao controle totalitário e monolítico da mente e do espírito humano. Por fim, a quinta concepção teórica identifica a necessidade de uma reformulação da ética capitalista, cujo princípio básico da propriedade deveria ser ampliado para um número maior de cidadãos, o que resultaria no incremento do sistema capitalista e na maior lealdade dos proprietários capitalistas.

Nesse quadro, Frederick (1960) afirma que o desenvolvimento da perspectiva da responsabilidade social no universo das corporações está relacionado à crescente conscientização em torno da produção e distribuição socialmente efetiva. Dessa forma, a responsabilidade social "implica uma postura pública em relação aos recursos humanos e econômicos da sociedade, significando que estes recursos devem ser utilizados objetivando amplos fins sociais" (Frederick, 1960, p. 60). Ainda segundo o autor,

$N$ ão existem fórmulas mágicas nem mecanismos automáticos que garantam os resultados que o público deseja. Consciência, somente, os homens de negócios cristãos não possuem o bastante. 0 equilíbrio de poder é igualmente insuficiente. É verdade que não podemos escapar totalmente de nossa herança cultural, mas, lentamente, estamos acumulando conhecimentos sobre nós mesmos e sobre os homens de negócios que podem possibilitar a resolução de alguns dos problemas relacionados à responsabilidade do negócio (FREDERICK, 1960, p. 61).

$\mathrm{N}$ a verdade, 0 intenso debate que envolve a perspectiva da responsabilidade social no ambiente dos negócios na sociedade americana, aliado ao desenvolvimento das políticas públicas oriundas do Estado de bem-estar social no continente europeu, faz com que - no ciclo de expansão das corporações multinacionais por meio dos investimentos diretos em todo o mundo - o desempenho social das corporações seja considerado uma importante variável não apenas para a formulação de estratégias, mas também para um contínuo relacionamento com a sociedade civil organizada. 


\section{Desempenho social corporativo}

Strand (1983) afirma que os objetivos e as metas que determinam e viabilizam a performance de qualquer organização, e os processos e os recursos humanos que originam os produtos ou serviços prestados, são restringidos e modelados pelo contexto sociocultural no qual a organização desenvolve suas atividades. Ou seja, "a performance social de qualquer organização não é uma componente distinta de sua efetividade como agente econômico" (Strand, 1983, p. 90). Segundo o autor, o estudo de adaptação das organizações ao ambiente social no qual estão situadas é limitado, principalmente, pelas definições inconsistentes de responsabilidade social e pela ausência de um paradigma aceitável que formalize estruturas de referência para a pesquisa científica.

As ações de adaptação das organizações ao ambiente podem ser analisadas por intermédio de três componentes. A primeira se refere ao desenvolvimento de demandas e expectativas sociais apresentadas à organização, ou seja, quais são as demandas sociais e que grupos pressionam a organização, que demandas sociais seriam de responsabilidade da organização, etapa conhecida como responsabilidade social. A segunda componente, denominada responsividade social, está associada aos processos organizacionais gerados quando as organizações recebem, interpretam e processam as demandas, o que implica perguntar: quais os processos adequados para tomar decisões relativas às demandas sociais? Com que processos as organizações implementam suas decisões? A terceira componente, nomeada resposta social da organização, refere-se às respostas específicas das organizações às demandas e ao controle dos resultados dessas respostas.

Sethi (1975) utiliza a expressão "desempenho social da corporação", acentuando que este é temporal e culturalmente determinado.

U ma ação específica é mais ou menos socialmente responsável apenas em uma estrutura temporal e ambiental sob referência das partes envolvidas. A mesma atividade empresarial pode ser considerada socialmente responsável sob um conjunto de circunstâncias em uma cultura e socialmente irresponsável em outro tempo sob diferentes circunstâncias (SETHI, 1975, p. 59).

0 autor define a legitimidade como o melhor indicador de avaliação de desempenho social das corporações. Sua justificativa é que a rel evância e validade de qualquer ação das corporações estão condicionadas à legitimidade na sociedade. Assim, o comportamento de qualquer corporação pode ser classificado como imbuído de obrigação social, responsabilidade social ou responsividade social.

Obrigação social é o comportamento da corporação em resposta às forças de mercado ou restrições de ordem legal. Epstein (apud Sethi, 1975) mostra que o critério legal é insuficiente para determinar a legitimidade da corporação porque negligencia os processos políticos e sociais. 0 critério legal, econômico tradicional é necessário, mas não suficiente, para a legitimidade da corporação, e afirma que "a corporação que infringir essa regra não sobreviverá" (Sethi, 1975, p. 62). A responsabilidade social é definida como a atitude cujas expectativas sociais ainda não foram codificadas em requisitos legais, não implicando al terações substanciais nas atividades relacionadas com 0 negócio da corporação ou no estilo de comportamento consagrado. O briga a corporação a desenvolver níveis mais altos de flexibilidade na atuação social. Por responsividade social é entendido o papel a ser desempenhado pela corporação a longo prazo, num contexto social dinâmico. Pressupõe que a corporação antecipe as prováveis mudanças futuras no cenário social, que podem ser resultantes da atuação da própria corporação ou de problemas sociais em que as corporações precisem desempenhar um papel significativo. N as palavras de Sethi, "as corporações devem iniciar políticas e programas que minimizem os efeitos adversos de atividades suas, presentes e futuras, que possam gerar crises e tornar-se catalisadoras de ondas de protestos" (Sethi, 1975, p. 63). As três etapas de classificação do comportamento das corporações definidas por esse autor estão relacionadas no Quadro 1.

Carroll (1979) define responsabilidade social das corporações como um conjunto de obrigações para com a sociedade e que estão incorporadas em quatro categorias: responsabilidade econômica, responsabilidade legal, responsabilidade ética e responsabilidade discricionária. Estas estão associadas respectivamente aos valores de produção de bens e serviços que a sociedade deseja, ao respeito às leis, ao respeito a padrões éticos, e ao fortalecimento de trabalhos voluntários. 0 autor propõe um modelo de desempenho social das corporações em que, além da dimensão responsabilidade social, estão presentes outras duas: responsividade social e áreas sociais em que as responsabilidades da corporação estão envolvidas (consumidor, meio ambiente, segurança do produto). Carroll associa a res- 
ponsi vidade social aos processos gerenciais de resposta às demandas sociais, variando em um contínuo de posturas, a saber, reativa, defensiva, de acomodação e proativa. Esse modelo tridimensional proposto pelo autor requer que a dimensão responsabilidade social seja definida pela corporação, que a área social seja identificada, para, posteriormente, a corporação qualificar a filosofia de resposta ou responsividade social.

$\mathrm{Na}$ realidade, as diversas concepções sobre performance social das corporações propiciaram o aprofundamento da discussão sobre a ética na gestão empresarial, consolidando um padrão de referência na relação com a sociedade. De acordo com Weber (1979), a ética é um discurso de legitimação e encontra-se no

Quadro 1 - Classificação: comportamento da corporação.

\begin{tabular}{l} 
Busca de legitimidade \\
Normas éticas \\
Indicadores sociais \\
para ações da corporação \\
Filantropia \\
\hline Estratégia operacional \\
\hline Resões governamentais \\
\hline
\end{tabular}

ESTÁGIO 1
OBRIGAÇÃO SOCIAL
itada a critérios legais e
nômicos.

Valor do negócio é neutro. Gerentes se comportam de acordo com seus próprios padrões.

Limitados aos interesses dos stakeholders.

Adaptação defensiva. Máxima exteriorização de custos.

Nega deficiências. Ignora insatisfação pública.

Resiste às atividades regulatórias exceto em situações para proteção de posição de mercado.

Busca manutenção do status quo e privilegia o lobby.

Contribui quando benefício direto é claramente demonstrado. coração da ideologia. Portanto, participa, juntamente com mecanismos simbólicos e políticos, de um sistema de reprodução das organizações. De acordo com Srour (1994), a ética é uma relação social, uma relação de forças, dependente de padrões morais específicos sob condições históricas precisas em que atuam agentes coletivos que buscam construir a hegemonia de seus valores morais peculiares. Srour mostra que toda organização desenvolve suas atividades em um ambiente hostil, em que todos os agentes procuram satisfazer seus próprios interesses. Os valores hegemônicos nas coletividades com as quais as corporações interagem pressionam estas a buscarem sintonia com esses valores, no sentido de preservarem a pró-

\section{ESTÁGIO 2 \\ RESPONSABILIDADE SOCIAL}

Aceita a limitação dos critérios legais e de mercado. Considera outras variáveis. Avaliação da performance social.

Estabelece normas para relacionar com as comunidades. Não enfrenta normas sociais.

Construídos para finalidades legais, mas ampliados para incluir os grupos afetados.

Adaptação reativa.

Assume responsabilidade na solução de problemas cotidianos.

Coopera com os governos para melhorar o padrão da indústria. Preserva discrição gerencial nas decisões corporativas.

Amplia o trabalho com grupos externos.

Contribui para causas estabelecidas e não controversas.
ESTÁGIO 3

RESPONSIVIDADE SOCIAL

Desempenha papel mais amplo no sistema social.

Advoga normas éticas institucionais mesmo se atingem seus próprios interesses.

Presta contas à sociedade de forma mais ampla.

Adaptação proativa. Antecipa futuras mudanças sociais.

Informação livre. Discute atividades com grupos externos.

Comunica-se abertamente com os agentes políticos, reforçando a legislação existente.

Auxilia o corpo legislativo a melhorar as leis vigentes.

Contribui para causas novas e controversas. 
pria imagem resguardando a continuidade do negócio. Assim, agir eticamente significa para as organizações estar em conformidade com a moral socialmente predominante, porque as relações travadas entre empresa e contrapartes são relações de força, relações de poder. Ainda de acordo com 0 autor,

Em outras palavras, parece inescapável reconhecer que, ao lado da função econômica, as empresas desempenham uma função ética. Os empresários terão de admiti-lo, não por altruísmo nem por repentino insight democrático, mas, pela imposição das relações de poder presentes. Agir eticamente, então, converte-se em questão de bom senso e em estratégia de sobrevivência. Cabe aqui ler o conceito de responsabilidade social como orientação para os outros, não por mera deliberação pessoal, mas como contingência dos interesses em jogo (SROUR, 1994, p. 10).

$\mathrm{N}$ a visão do autor, a empresa capitalista - mesmo estando em um ambiente social composto por códigos morais - apenas se comporta de acordo com uma ética de responsabilidade social quando seus interesses de reprodução estão sob risco. A gestão empresarial moldada pela ética é resultante de uma relação de forças entre atores internos e externos ao universo organizacional. Conforme proposto por M intzberg (1983), uma relação de poder em que se apresentam influenciadores internos e externos que formam coalizões que se relacionam sob a forma de barganha.

Srour (1994) estabelece uma associação importante entre abordagem ética, ideologia econômica e ideologia política. Para o autor, é importante distinguir entre uma ética da realização pessoal, elitista, individualista, de base calvinista, de outra ética da salvação e do dever, paternalista, assistencialista e altruísta, de base católica. Essas duas visões originam ações fundamentadas em princípios relacionados à ética, aos valores humanos e à cidadania corporativa. A própria construção teórica sobre a importância da percepção de responsabilidade social por parte das empresas, desenvolvida sob os princípios da moral protestante, está relacionada à concepção da sociedade capitalista, ao fundamento econômico e de gestão das empresas, ao ordenamento institucional da sociedade (Alves, 2003).

A partir de uma leitura de Bowen, Alves (2003) demonstra a preocupação do autor na formulação da doutrina da responsabilidade social corporativa como instrumento para a defesa dos val ores da livre iniciati- va e conten ção da intervenção do estado na economia em um contexto (década de 1950) de ameaça à "ordem estabelecida". A evocação voluntária dessas responsabilidades pelos homens de negócios é, ao menos, uma al ternativa possível para se evitar um maior controle da economia pelo Estado. Por meio do fundamento econômico e da gestão profissional, as empresas procuram obter a taxa de retorno do empreendimento enfatizando relações internas e externas, e otimizando o gerenciamento a partir da mudança de valores da cultura organizacional, em que os administradores profissionais são incitados a romper com a opinião tradicional de que só importa o acionista para sobreviver num mundo mais democrático e restritivo das ações empresariais (Alves, 2003). Partindo dos preceitos apontados pelo autor, é possível investigar como as corporações trabal ham os valores da responsabilidade social no universo da estratégia organizacional, resultando em ações orientadas para o marketing, seja na construção de parcerias intituladas de desenvolvimento local ou por meio de atividades filantrópicas, com destaque para 0 incentivo ao voluntariado.

Os estudos desenvolvidos por Carrion e Garay (2000) indicam maior preocupação por parte das corporações pelo denominado "investimento social privado". A prática da filantropia cede lugar a crescentes iniciativas de fortalecimento de parcerias estratégicas para a execução de projetos localizados e monitorados pelas próprias corporações, bem como de trabal hos voluntários liderados pelos próprios agentes das organizações, particularmente em campanhas de apelo social. Isso pode demonstrar que as organizações encontram dificuldade em convencer a audiência externa se a audiência interna não estiver aceitando a mensagem, produzindo processos de comunicação externos e internos interligados (Cheney e Christensen, 2001).

Garay (2001) desenvolveu pesquisas buscando compreender as principais razões do crescimento do voluntariado empresarial. De acordo com esse autor, o voluntariado possibilita - além da consolidação de uma imagem corporativa favorável - 0 aumento do nível de identidade dos voluntários com a empresa, 0 estímulo ao desenvolvimento do papel institucional do executivo, o fortalecimento da cultura corporativa e maiores oportunidades para o desenvolvimento de competências funcionais. Essa análise é corroborada por Falconer e Fischer (2001), ao pesquisarem a relação entre estratégia e voluntariado empresarial. 


\section{PROCEDIMENTOS METODOLÓGICOS}

0 método de pesquisa destinado a investigar os programas desenvolvidos pela organização sob a denominação da responsabilidade social foi desenvolvido por meio de um conjunto de entrevistas semi-estruturadas versando sobre políticas de desenvolvimento local, preservação ambiental e concepção de responsabilidade social. Foram envolvidos 10 agentes políticos, ambientalistas, microempreendedores, lideranças comunitárias na região de atuação da empresa, al ém da utilização das fontes oficiais da organização sobre as iniciativas de cunho social. As análises relacionadas à pesquisa foram construídas a partir da utilização da análise do discurso, que possibilita o estudo da estrutura lingüística dos atos de fala buscando as relações com normas, preferências e expectativas sociais, culturais e políticas. Os discursos dos personagens refletem representações ideológicas, uma visão de mundo, o ponto de vista a respeito da realidade, a justificativa e a explicação da ordem social. 0 texto - manifestação dos personagens envolvidos no contexto de atuação da organização - é o encontro de um plano de conteúdo, em que se localiza o discurso, com um plano de expressão, que no universo empresarial se materializa via mídia escrita, oral e nos trabal hos cotidianos com as comunidades (Fiorin, 1988).

A análise do discurso explora como as idéias socialmente produzidas e incorporadas nas organizações são criadas e mantidas por meio do relacionamento entre discurso, texto e ação. Na perspectiva de Phillips, Lawrence e Hardy (2004), as instituições não são somente construções sociais, mas construções sociais que se constituem por meio do discurso. Essa análise é corroborada por Fairclough (1995, p. 38), ao afirmar que "toda instituição social é um aparato de interações verbais, ou uma ordem discursiva, que facilita e restringe a ação social de seus membros, fornecendo uma estrutura social para ação de seus integrantes".

De acordo com Phillips, Lawrence e Hardy (2004), as instituições são produzidas e reproduzidas por intermédio de processos de institucional ização, que tornam possíveis certos caminhos de pensar e atuar. Pela óptica discursiva, a implicação é "que as instituições são construídas primariamente mais através da produção de textos do que por ações" (Phillips, Lawrence e Hardy, 2004, p. 638). Entretanto, ainda segundo os autores, as ações afetam o discurso por meio da produção de textos objetivando a constituição de um modo discursivo de institucionalização. Isso se dá pela produção inicial de um significado lingüístico no qual se combinam palavras que envolvem narrativas, metáforas e formas simbólicas que necessitam ser legitimadas na sociedade, gerando a produção de textos no intuito de manter ou mudar o significado associado às ações. Os textos são incorporados em formações discursivas quando são adotados como significados generalizados, sustentados e interligados a um universo discursivo consensualmente validado, o que confere legitimidade ao produtor do texto. Um texto tem maior probabilidade de influenciar o discurso quando evoca outros textos, quando a interdiscursividade habilita 0 texto a se projetar noutros discursos para manter sua legitimidade e seu significado (F airclough, 2001).

N esse sentido, a análise da pesquisa procura inicialmente identificar como a organização produz o que Phillips, Lawrence e Hardy (2004) denominam categorias sociais, que formatam a compreensão e o comportamento dos atores em relação à responsabilidade social, produzindo uma ordem social que dificulta a adoção de comportamentos que não sejam legitimados por ela, resultando em disputas originárias de relações de poder. A produção da ordem social ocorre via linguagem, um recurso convencional para influenciar a atitude e o comportamento das pessoas por intermédio da persuasão, argumentação ou utilização de ameaças, em que 0 enunciador despolitiza a mensagem, tornando mais palatável o exercício da influência. Dessa forma, referenda-se que grupos mais bem posicionados nas relações de poder produzem formações discursivas aceitas para uso geral (Bradac e Hung Ng, 1993).

Sen do uma pesquisa de natu reza qual itativa, a legitimidade das proposições inferidas não deve repousar no número de casos ou de instâncias, mas no modo de lidar com o essencial na explicação das regularidades descobertas (Fernandes, 1973). Assim, a base de dados foi construída por intermédio da análise de documentos públicos da organização e entrevistas semiestruturadas com integrantes da organização, agentes políticos e lideranças comunitárias. Partindo de um protocolo de estudo de caso (Yin, 2001), o trabalho de campo se baseou em observação direta, procurando interações sociais informais para uma maior confiabilidade das evidencias, objetivando documentar um fenômeno de interesses por meio do conhecimento dos comportamentos, crenças e atitudes associadas à ocorrência de tal fenômeno.

\section{Caracterização da empresa}

A organização envolve a parceria entre uma empresa 
multinacional e outra brasileira. A partir de 2001, em uma negociação avaliada em US\$ 600 milhões, o parceiro internacional adquiriu integral mente o controle acionário. A empresa atua em 47 municípios no estado de M inas Gerais, gerando aproximadamente 9 mil empregos diretos e 27 mil indiretos, destinando quase toda a produção para o mercado externo. A principal fonte de matéria-prima da empresa é a floresta de eucaliptos, sendo por ela reconhecida em compromisso público via código de ética da organização. Detentora de certificações ISO 9001 e ISO 14001, a empresa desenvolve programas sociais sob a perspectiva da responsabilidade social com iniciativas geralmente focadas nas áreas educacional, ambiental e de produção agrícola.

A organização desenvolve programas como Ação e Cidadania nas comunidades, envolvendo atendimento médico, jurídico, campanhas educativas e de entretenimento infantil. As ações implementadas pela organização sob o lema da responsabilidade social são formuladas por intermédio do Instituto de Ação e Cidadania, constituído para a execução de parcerias agrícolas, culturais e socioambientais na área de atuação da organização. A análise da pesquisa busca identificar, por meio das formações discursivas dos diversos atores, as estratégias de persuasão utilizadas no intuito da promoção de influência nas relações de poder, já que as estratégias de persuasão confirmam que a linguagem afeta e é afetada pelas relações de poder entre os diversos grupos sociais (Bradac e Hung N g, 1993).

\section{ANÁLISE E DISCUSSÃO}

A atuação da gerência da organização nas comunidades tem sido alvo de conflitos envolvendo administradores municipais, ambientalistas e parlamentares. Em decorrência da visão de cidadania corporativa, a gerência da organização, influenciador interno, apresenta publicamente os seguintes princípios no código de ética da corporação:

- nas comunidades onde atua, a empresa priorizará o respeito e estabelecerá parcerias voltadas para ações que promovam a melhoria da qualidade de vida da comunidade, buscando desenvolver e preservar a cultura local, e minimizar os impactos decorrentes de suas atividades;

- a empresa contribui para a preservação do meio ambiente conforme determinações legais definidas em sua política ambiental por entender a importância do tema para o desenvolvimento de seu negócio, com base no conceito de crescimento sustentável e sua importância para as comunidades inscritas em sua área de atuação.

Por meio da bandeira de "melhoria da qualidade de vida nas comunidades", a organização desenvolve nos municípios ações sociais como distribuição de calçados e material escolar para o ensino fundamental, além de disponibilizar pequenas áreas para a plantação e 0 cultivo sob agricultura familiar. É importante observar no discurso oficial da organização a preocupação com o social. 0 texto produzido pela gerência da organização é individual, mas o conteúdo do discurso é caracterizado pelo contexto social em que a organização está inserida, o da valorização do lema da responsabilidade social pelas corporações. Como agente enunciador, o dizer da gerência da organização é a reprodução inconsciente do dizer de seu grupo social, não sendo ela livre para dizer, mas coagida a dizer 0 que seu grupo diz (Fiorin, 1998). É a busca de sintonia com o discurso hegemônico no intuito de preservar a própria imagem (Srour, 1994). Enquanto o discurso é a materialização das formações ideológicas, a forma como a gerência apresenta as ações que compõem a doutrina da responsabilidade social é o espaço reservado à manipulação consciente, cujos el ementos de expressão são organizados da melhor forma para veicular o discurso. Segundo Fiorin (1998, p. 42), "o discurso é, pois, o lugar das coerções sociais, enquanto 0 texto é o espaço da liberdade individual".

O discurso formalizado na sintaxe "[...] a empresa contribuirá para a preservação do meio ambiente, conforme determinações legais definidas em sua política ambiental $[. .$.$] " pode ser entendido como uma estra-$ tégia discursiva de persuasão ideológica baseada no silêncio (Faria, 1992), pois privilegia o dito "contribuirá para a preservação do meio ambiente tendo como referência sua política ambiental", silenciando as concepções dos outros agentes sociais com relação aos impactos das atividades da organização sobre o meio ambiente. De acordo com M intzberg (1983), é o reflexo de uma relação de poder em que a coalizão interna da organização procura dominar a influência dos enunciadores, influenciadores, presentes na coalizão externa. Esse autor qualifica essa forma de intervenção como a priorização de objetivos econômicos e sociais numa perspectiva puramente gerencial.

Um ponto comum das entrevistas coletadas é o envolvimento de controle social e poder. As manifestações dos agentes discursivos demonstram que não existe um relacionamento externo entre linguagem e so- 
ciedade, mas um relacionamento interno e dial ético (Fairclough, 1989). Isso é ilustrado com os depoimentos a seguir:

Nós não abrimos mão de um debate amplo sobre a atuação da empresa nos municípios. A relação da empresa com as comunidades não pode se limitar a meras atividades filantrópicas. É preciso diminuir a ganância e pensar na vida humana, na destruição da biodiversidade, na destruição do tecido social, provocada pela expansão da monocultura do eucalipto" (Formação discursiva 1 - Deputado estadual).

O nosso município é pobre, vivemos de um pequeno comércio e produção agrícola. Cresceram muito as plantações de eucalipto, mas a empresa atende os nossos pedidos, principalmente na educação municipal, com a doação de material escolar e na infra-estrutura com a ajuda na manutenção das nossas estradas. Evitamos participar muito do conflito levantado pela ONG, que existe aqui na região, porque na realidade o poder da empresa é muito grande" (Formação discursiva 2 - Prefeito do município A).

É possível distinguir nas formações discursivas tipos diferenciados de restrições exercidas por um agente sobre outro, em uma autêntica relação de poder: na formação discursiva 1, 0 "não abrir mão de um debate amplo sobre a atuação da empresa $X$ nos municípios", o enunciador deixa implícita uma restrição de relacionamento social (Fairclough, 1989), em que a organização mantém relação de domínio utilizandose do instrumento da audiência restrita. $\mathrm{Na}$ formação discursiva 2, "evitamos participar muito de conflito [...] porque, na realidade, o poder da empresa é muito grande", o enunciador expressa uma restrição do papel do sujeito (Fairclough, 1989), em que este ocupa uma posição de total subordinação no relacionamento com a organização.

Empreendimento com responsabilidade social deve ser ecologicamente correto, economicamente viável e socialmente justo. Para a empresa $X$, só val e o economicamente viável, e da mesma forma que ela atua na política nos diversos municípios. Também já está influenciando no nosso conselho municipal de defesa do meio ambiente, para desestabilizar a atual direção (Formação discursiva 3 - Presidente do consel ho municipal de meio ambiente do município B).
As atividades da empresa $X$ estão transformando a nossa região em pequenas comunidades ilhadas por eucaliptos, onde as atividades agrícolas são destruídas. A responsabilidade social da empresa, diferente do dito, deveria se dar na perspectiva da preservação ambiental e do desenvolvimento econômico regional, o que não existe (F ormação discursiva 4 - Diretor de meio ambiente da prefeitura do município B).

É possível observar que a formação discursiva 3, em que "para a empresa só vale o economicamente viável", indica uma restrição de conteúdo (Fairclough, 1989) em relação ao universo do agente enunciador. Demonstrando ainda, via enunciação, "já está influenciando no nosso consel ho municipal de meio ambiente para desestabilizar a atual direção", uma restrição do papel do sujeito, garantindo a dominação da organização por meio da subjugação do agente enunciador. $\mathrm{N}$ a formação discursiva 4, "a responsabilidade social da empresa $X$, diferente do dito, deveria se dar na perspectiva da preservação ambiental", apresentase uma restrição de conteú do em que o agente enunciador conclui por uma atuação da organização diferente do publicamente enunciado. Assim, o publicamente enunciado equivale ao "poder ideológico, o poder de projetar práticas próprias, tendo como base o senso comum, que é significativo complemento para o poder político e econômico" (Fairclough, 1989, p. 33).

$\mathrm{Na}$ formação discursiva 5, o enunciador questiona os programas implantados pela organização:

0 que é responsabilidade social? É a empresa $X$ reduzir o número de nascentes de água da região de 280 para 95? As atividades filantrópicas desenvolvidas por ela junto às comunidades que perpetuam o poder são de fato uma preocupação social? Qual o sentido do investimento em treinamento ambiental feito pela empresa maciçamente com os professores em toda a região, tendo como base estritamente sua política ambiental? (Formação discursiva 5 - Dirigente de ONG atuante na região).

Merece destaque o enunciado "qual o sentido do investimento em treinamento ambiental feito pela empresa maciçamente com os professores em toda a região tendo como base estritamente sua política ambiental", em que está presente uma restrição de conteúdo por parte da organização com o objetivo de le- 
gitimar a dominação. Segundo Fairclough (1989), em qualquer sociedade existirão mecanismos para realizar a social ização das práticas relacionadas a conhecimentos e crenças, relações e identidades sociais. A coordenação imposta no exercício do poder é denominada doutrinação, dessa forma, "qualquer sistema educacional é um caminho político de manter ou modificar a apropriação de discursos através dos conhecimentos e poderes que eles conduzem" (Fairclough, 1989, p. 65). 0 treinamento promovido pela organização junto aos professores é uma iniciativa de gerenciar as interações com o ambiente social, uma peça de reprodução contínua dos valores da gerência da organização (Phillips e Brown, 1993).

As formações discursivas 6 e 7 mostram que a forma lingüística sempre se apresenta aos locutores num contexto ideológico preciso. N esse sentido, a situação social mais imediata e o meio social mais amplo determinam completamente a estrutura da enunciação (Bakhtin 2004), como mostrado a seguir:

A nossa empresa possui padrão internacional. Assim, nós necessitamos preocupar com nossos colaboradores, os empregados e a sociedade, que se relacionam conosco. A responsabilidade social é a ética que guia nossas ações, conforme as grandes organizações (Formação discursiva 6 - Gerente 1 da organização).

A empresa exige em nossas ações sempre pensarmos no social. Os nossos programas de atendimento às comunidades atendem as necessidades em diversas áreas que fazemos questão de contemplar no planejamento estratégico empresarial. Podemos destacar as áreas de educação e meio ambiente como principais (Formação discursiva 7 - Gerente 2 da organização).

As enunciações reproduzem um produto puro da interação social, a incorporação da ideologia da responsabilidade social pelas corporações. 0 indivíduo fala a linguagem de seu grupo, pensa do modo que seu grupo pensa, ou somente num sentido muito limitado pode criar por si mesmo um modo de falar e pensar (Mannheim, 1968).

No Relatório da Diretoria de 2003, a gerência da organização considera que ocorreram melhorias substanciais no relacionamento com os diversos stakeholders. Faz um balanço positivo dos projetos sociais desenvolvidos, embora não disponibilize publicamente 0 balanço social. De acordo com Puppim (2003), a pu- blicação de balanços sociais é prática comum das maiores empresas, 0 que possibilita informações sobre 0 modo como as organizações desempenham suas funções sociais.

\section{CONSIDERAÇÕES FINAIS}

A ideologia da responsabilidade social empresarial tem sua origem em uma geopolítica mundial em tensão por uma disputa ideológica envolvendo o liberal ismo, particularmente a escola neoliberal, e o crescente movimento pela intervenção do Estado na economia, por meio da concepção do Estado de bem-estar social, materializado pela social-democracia européia. Esse debate socioeconômico no período de reconstrução da economia capitalista no contexto da guerra fria, pósSegunda Guerra Mundial, está presente nos postulados de H. Bowen (1953), ao afirmar a doutrina da responsabilidade social como uma alternativa possível para se evitar um maior controle da economia pelo Estado. Em meio ao conflito entre a teoria neoliberal e a concepção da responsabilidade social corporativa, vale destacar as manifestações que indicam a preocupação em torno da ética nos negócios como necessária para a própria sobrevivência das organizações, devido às relações de poder que envolvem as organizações e os diversos influenciadores externos. Conseqüentemente, a ideologia da responsabilidade social demonstra a preocupação das organizações com a pressão dos influenciadores externos nas relações sociais de poder, resultado de mudanças sociais que impulsionaram a aceitação de novas normas, que, por sua vez, tornaram comportamentos anteriores social mente inaceitáveis. $\mathrm{N}$ a realidade, o discurso da ideologia liberal, do negócio estritamente associado ao lucro, tornou-se contraproducente para as exigências de diferenciação na economia capital ista competitiva.

Da hegemonia do discurso da responsabilidade social no ambiente empresarial decorre a relevância do desempenho social das corporações, em que ações sociais são mensuradas por intermédio de balanços específicos que possibilitam a institucionalização de comportamentos e a difusão de políticas de marketing no mercado. Isso significa que há uma batal ha em busca das mentes das pessoas numa estrutura social que val oriza imagens de representação e a manipulação de símbolos (Castells, 1999).

Sob a tipologia proposta por Sethi (1975) acerca do desempenho social das corporações, a organização 
deste estudo de caso pratica um conjunto de ações enquadradas na definição de obrigação social, particularmente na compreensão das normas éticas como estritamente associadas ao padrão estabelecido pela gerência da organização, na postura de resposta às pressões sociais, ignorando a insatisfação de agentes políticos referenciados na sociedade. Isso conduz à priorização da execução de projetos filantrópicos nas comunidades em substituição à formação de parcerias objetivando o fortal ecimento da economia regional. $\mathrm{Na}$ realidade, o comportamento da organização em relação à ideologia da responsabilidade social é motivado pela insuficiência de legitimidade derivada exclusivamente do atendimento aos padrões exigidos de ordem legal e econômica no mercado.

A ideologia da responsabilidade social, incorporada pela organização, faz parte de um movimento de resposta aos ataques sofridos pelas grandes corporações, que são percebidas como sistemas fechados, de legitimidade questionável, com enorme poder político, econômico e social. Por intermédio desse movimento, a organização desenvolve uma intervenção mais qualificada em direção à dominação dos influenciadores externos nas relações de poder. Aliada à pratica filantrópica, a organização, ao desenvolver programas comunitários, busca não apenas o fortalecimento da própria imagem, como também o desenvolvimento interno de competências. Em virtude da concepção da ideologia da responsabilidade social como uma pura peça da estratégia empresarial, a gerência da organização visual iza as possíveis contribuições ou rei vindicações de outros atores sociais, organizad os como pontos geradores de conflitos, o que impossibilita uma relação mais equilibrada de poder. De outra forma, a tensão resultante no cenário de atuação da organização em decorrência das disputas com influenciadores externos organizados impede a constituição de barganha de natureza integrativa nas relações de poder, em que poderiam ser exploradas iniciativas conjuntas que potencializassem o desenvolvimento econômico e social sustentável.

Numa relação de poder em que um conjunto de atores permanece inteiramente submisso, a interface organização-sociedade é realizada sob uma única via. A difusão da ideologia da responsabilidade social essencialmente sob a óptica gerencial acaba ocultando um antigo debate sobre o controle das corporações na sociedade, reduzindo-o a uma discussão dicotômica entre a prática ou não da cidadania corporativa. Assim, o comportamento das cor- porações, que na realidade se encerra nas relações de poder que envolvem grupos de pressão na sociedade, é traduzido pela visão hegemônica da gerência. Portanto, a pressão dos influenciadores externos sobre a organização é importante não só para a rediscussão da governança corporativa, mas também para compensar o poder resultante das prerrogativas de natureza gerencial.

\section{REFERÊNCIAS BIBLIOGRÁFICAS}

ALVES, E. Dimensões da responsabilidade social da empresa: uma abordagem desenvolvida a partir da visão de Bowen. Revista de Administração, São Paulo, v. 38, n. 1, p. 37-45, 2003.

BAKHTIN, M. M arxismo e filosofia da linguagem. São Paulo: Hucitec, 2004.

BOWEN, H. Social Responsabilities of the Businessman. New York, 1953.

BRADAC, J.; NG, HUNG. Power in Language. London: Sage, 1993. v. 3.

CARRION, R.; GARAY, A. Organizações privadas sem fins lucrativos: a participação do mercado no terceiro setor. Análise, Porto Alegre, v. 11, n. 1, p. 203-222, 2000

CARROLL, A. Three-dimensional conceptual model of corporate performance. Academy of Management Review, v. 4, n. 4, p. 497-505, 1979.

CASTELLS, M. A Era da Informação: o poder da identidade. São Paulo: Paz e Terra, 1999. v. 2.

CHENEY, G.; CHRISTHENSEN, L. Organizational identity. In: The New Handbook of Organizational Communication. London: Sage, 2001. p. 231269.

FAIRCLOUGH, N. Language and Power. N ew York: Longman Inc., 1989.

FAIRCLOUGH, N. Critical Discourse Analysis: The Critical Study of Language. London: Longman, 1995.

FAIRCLOUGH, N. Discurso e mudança social. Brasília: Ed. UNB, 2001.

FALCONER, A.; FISCHER, R. Voluntariado empresarial: estratégias de empresa no Brasil. Revista de Administração, São Paulo, v. 36, n. 3, p. 1527, 2001.

FARIA, A. M. 0 preço da passagem no discurso de uma empresa de ônibus. Departamento de Lingüística, FALE/UFMG, Belo Horizonte, p. 1-7, 1992.

FERNANDES, S. Fundamentos empíricos da explicação sociológica. São PauIo: Queiroz/EDUSP, 1973

FIORIN, L. J. Linguagem e ideologia. São Paulo: Ática, 1998.

FREDERICK, W. The growing concern over business responsibility. California Management Review, v. 2, p. 54-61, 1960.

FRIEDMAN, M. Capitalismo e liberdade. São Paulo: Nova Cultural, 1988. 
GARAY, B. A. Programa de Voluntariado Empresarial: modismo ou elemento estratégico para as organizações? Revista de Administração, São PauIo, v. 36, n. 3, p. 6-14, 2001.

HAYECK, F. O caminho da servidão. Porto Alegre: Globo, 1977.

JONES, T. An integrating framework for research in business and society: a step toward the elusive paradigm? Academy of Management Review, v. 8 , n. 4, p. 559-564, 1983.

KUHN, T. A estrutura das revoluções científicas. São Paulo: Perspectiva, 1970.

LEVITT, T. The dangers of social responsibility. Harvard Business Review, p. 41-50, sep.-oct.,1958.

MANNHEIM, K. Ideologia e utopia. Rio de Janeiro: Zahar, 1968.

MCINTOSH, M. Cidadania corporativa - estratégias bem-sucedidas para empresas responsáveis. Rio de Janeiro: Q ualitymark, 2001.

MINTZBERG, H. Power in and around O rganizations. Englewood Cliffs, NJ: Prentice Hall, 1983.

PHILLIPS, N.; LAWRENCE, T.; HARDY, C. Discourse and institutions. Academy of M anagement Review, v. 29, n. 4, p. 635-652, 2004.

PHILLIPS, N.; BROWN, J. Analyzing communication in and around organizations: a critical hermeneutic approach. Academy of $M$ anagement Journal, v. 36, n. 6, p. 1547-1576, 1993.
PUPPIM, J. Um balanço dos balanços sociais das 500 maiores empresas S.A. não-financeiras do Brasil. In: ENCONTRO NACIONAL DA ASSO CIAÇÃO NACIONAL DOS PROGRAMAS DE PÓS-GRADUAÇÃO E PESQUISA EM ADMINISTRAÇÃO, 27., 2003, Atibaia. Anais. Atibaia: AN PAD, 2003.

PRESTON, L. Corporation and society: the search for a paradigm. Journal of Economic Literature, p. 435-453, 1975.

PRESTON, L. E.; POST, J. E. Private management and public policy. California Management Review, v. 23, n. 3, p. 58-62, 1981.

SETHI, P. S. Dimensions of corporate social performance: an analytical framework. California Management Review, v. 13, n. 3, p. 58-64, 1975.

SROUR, R. Ética empresarial sem moralismo. Revista de Administração, São Paulo, v. 29, n. 3, p. 2-22, 1994.

STRAND, R. A Systems paradigm of organizational adaptations to the social environment. Academy of Management Review. v. 8, n. 1, p. 90-96, 1983.

WARTICK, S.; COCHRAN, P. The evolution of the corporate social performance model. Academy of Management Review, v. 10, n. 4, p. 758-768, 1985.

WEBER, M. Ensaios de sociologia. Rio de Janeiro: Zahar, 1979.

YIN, R. Estudo de caso, planejamento e métodos. Porto Alegre: Bookman, 2001.

\section{Artigo recebido em 23.08.2004. Aprovado em 18.07.2005.}

\section{Epaminondas Bittencourt}

Secretário de Administração e Recursos Humanos, Prefeitura M unicipal de Nova Lima - M G e membro do GGI/UFMG-CEPEAD. Mestre em Administração pela UFM G-CEPEAD.

Interesses de pesquisa nas áreas de relações de poder, identidade, liderança e cultura organizacional.

E-mail: ebn@cepead.face.ufmg.br

Endereço: Rua Curitiba 832, Centro, Belo Horizonte - M G, 30170-120.

\section{Alexandre C arrieri}

Professor da UFM G-CEPEAD e coordenador do GGI/UFM G-CEPEAD. Doutor em Administração pela UFMG-CEPEAD.

Interesses de pesquisa nas áreas de cultura e identidade organizacional.

E-mail: alexandre@cepead.face.ufmg.br

Endereço: Rua Curitiba 832, Centro, Belo Horizonte - MG, 30170-120. 